$\underline{\text { Article }}$

\title{
If It Works Here, How Can We Make It Work Anywhere? Reputation Transfer Across Borders.
}

\author{
Theresa Bernhard ${ }^{1}$ a \\ 1 Friedrich-Alexander-Universität Erlangen-Nürnberg, Germany \\ Keywords: corporate reputation, reputation transfer, interview study \\ https://doi.org/10.46697/001c.28211
}

\section{AIB Insights}

Vol. 21, Issue 3, 2021

Firms with a positive home country reputation should be highly motivated to transfer their reputation abroad when they internationalize. This article presents the results of interviews with corporate reputation specialists and develops practicable insights for managers. It finds that the comprehensive understanding of the firm's reputation among the variety of its home country stakeholders is necessary for corporate reputation transfer. Then, the firm needs to empower reference stakeholders to become reputation ambassadors, who must credibly communicate about the firm's positive reputation with prospective stakeholders in the host market. Moreover, firms should utilize social media as a tool for cross-border reputation transfer.

\section{INTRODUCTION}

Can positive firm reputation earned in the home country be transferred to a foreign country during internationalization? Stakeholders construct a firm's reputation by assessing its ability to "create value relative to competitors" (Rindova, Williamson, Petkova, \& Sever, 2005: 1033). When this assessment is favorable, a positive reputation is ascribed to the firm (Makarius \& Stevens, 2019). Corporate reputation can be understood as a resource, which may yield a competitive advantage for the firm, for instance through superior performance (Roberts \& Dowling, 2002). A firm that is internationalizing has most likely already gained a positive reputation in the home market, as this positive reputation gives it access to those resources necessary for internationalization (financial resources, human resources, etc.) (Mukherjee, Makarius, \& Stevens, 2021). In the host market, however, the firm is confronted with liabilities of foreignness and outsidership (Johanson \& Vahlne, 2009). Prospective, foreign stakeholders in the host country lack relationships with the firm and, therefore, hold limited to no information about the corporation, its character and its capabilities, and are not able to assess the firm's ability to create value. This challenge is further intensified by the corporation's foreignness. Subsequently, these liabilities may impede the construction of a favorable corporate reputation among stakeholders in the host country. Hence, when internationalizing to a new country, firms with a positive home country reputation should likely be motivated to transfer their reputation across borders, thereby exploiting an already existing competitive advantage.

The objective of this article is to present applicable in- sights for managers on how to transfer corporate reputation obtained in the home country to a foreign country. I realize this aim by briefly reviewing the extant research on the topic, by drawing from interviews with corporate reputation specialists and by deriving concrete and practicable implications for managers. At the end of this article, I delineate the boundaries of cross-border reputation transfer that managers of global organizations must recognize.

\section{REPUTATION TRANSFER DURING FIRM INTERNATIONALIZATION}

Reputation transfer denotes the shifting of favorability from a current to a future context (Mukherjee et al., 2021). Prevailing literature on reputation transfer or reputation spillover has mostly focused on the transfer of reputation between different organizations. With few positive exceptions (Paruchuri, Pollock, \& Kumar, 2019), scholarly attention has mostly been directed towards analyzing reputation spillover in negative or crisis situations (Norheim-Hansen \& Meschi, 2020). Generally, the transfer of intangible organizational resources, such as corporate reputation, across national borders remains conceptually and empirically under-researched. Theory, such as the resource-based view of the firm, suggests that the exploitation of existing assets as well as the augmentation of resources to create new resources are ways to generate value for the firm (Barney, 2001). In the context of firm internationalization, exploitation involves transferring existing resources, such as a firm's reputation, from the home country to the host country (Mukherjee et al., 2021). In the light of liabilities of outsidership and foreignness that challenge the construction 
of a reputation, firms with a positive reputation in their home country should be motivated and highly interested in transferring their positive reputation to their host country in the process of internationalization. Due to its intangible nature and its dependence on local stakeholders, corporate reputation is particularly challenging to transfer across borders. For instance, recent empirical research finds that reputation varies across countries (Soleimani, Schneper, \& Newburry, 2014) and national cultures (Deephouse, Newburry, \& Soleimani, 2016). Hence, the lack of scholarly attention on how firms can transfer reputation transfer during internationalization is surprising, as this research could provide managers with valuable insights and recommendations (Newburry, Deephouse, \& Gardberg, 2019).

\section{THE CURRENT STUDY}

Therefore, this study presents the results of five qualitative interviews with corporate reputation specialists, which were conducted in connection with a larger research project. The interviewees work either as corporate reputation managers in German multinational companies in the automotive and consumer electronics sectors or as consultants focusing on corporate reputation consulting in multinational consultancy firms. They have between 3.5 and 15 years work experience in the domain of corporate reputation. The sample for this study consists of five male interviewees from Germany and the interviews took between 30 to 70 minutes time.

I recruited each interviewee through a professional social media network and conducted the interviews in German via telephone or video call, depending on the interviewees' preferences. Detailed information on the purpose of the study and their anonymity was provided to the interviewees at the beginning of each interview. A semi-structured interview guide allowed me to follow-up on interesting and relevant aspects mentioned spontaneously by the participants. The interview data were recorded, transcribed, translated into English and back-translated into German to check for consistency, content-coded, and analyzed. Afterwards, these codes were categorized into three overarching themes related to the research topic (understanding one's current reputation in the home country, utilizing reference stakeholders as ambassadors for one's reputation, exploiting social media as a tool for reputation transfer) and will be presented in the following.

\section{FINDINGS AND THEIR IMPLICATIONS}

\section{REPUTATION IN HOME COUNTRY: FINDINGS}

An initial common theme that emerged in the descriptions of successful and failed cross-border reputation transfer relates to the understanding of a corporation's current reputation. All interviewees partly attributed failed reputation transfer to firms' missing understanding of their reputation in the home country. Hence, an integral precondition of corporate reputation transfer is a comprehensive understanding of one's current reputation in the home market, which according to the interviewees only very few companies have. While this challenge exists for companies world-

wide, particularly European firms lack these insights. The poor understanding might also be due to a more profound disregard for the variety of different stakeholders. In fact, the managerial focus is often mainly concentrated on the perceptions of their direct consumers as their target group, thereby neglecting the diversity of other stakeholders with their needs. Consequently, firms frequently fail to identify those stakeholders that primarily drive their reputation, and fail to understand how those stakeholders construct the firm's reputation. The following statement from one of the interviews was selected to illustrate this argument:

"To be able to transfer reputation from your home country,
and to benefit from your positive reputation abroad, you
have to, of course, first understand why you have such a
good reputation at home. And, from my experience, most
companies do not have that understanding. Look at Ger-
many, look at Central Europe - I do not think that there
are many companies that actually know what reputation
they have, let alone strategically use their reputation to
get in contact with foreign stakeholders." [Interviewee 3,
Corporate Reputation Consultant]

\section{REPUTATION IN HOME COUNTRY: MANAGERIAL} IMPLICATIONS

Despite it being a prerequisite for transferring a positive reputation abroad during internationalization, corporations are frequently lacking comprehensive insights into their reputation among all of their home country stakeholders. Consequently, the competitive advantage of a positive home country reputation cannot be exploited when going abroad. Hence, managers should be motivated to gain this knowledge, for instance through reputation monitoring. Here, the main challenges rest in selecting suitable monitoring tools, selecting appropriate questions to evaluate reputation as well as translating the findings from reputation monitoring into managerial decisions. One practical example for how reputation monitoring can look like is presented by Rust and colleagues (2021), whose social media reputation tracker allows for the monitoring and management of a corporation's reputation on different social media platforms over time.

In addition, beyond the topic of cross-border reputation transfer, the interviewees criticized that many corporations are also underestimating and failing to recognize the overarching relevance of reputation for the realization of their economic and non-economic business goals. Based on this, I suggest that managers invest in developing a mindset for reputation within their companies, for instance, through recruiting corporate reputation specialists involved in internationalization decisions and related projects.

\section{REFERENCE STAKEHOLDERS: FINDINGS}

All interviewees further emphasized the significant influence of reference stakeholders for the success or failure of cross-border reputation transfer. These reference stakeholders from the home country should act as reputation ambassadors and be asked to consistently and openly share their views on the corporation's reputation with prospective stakeholders in the host country. To do this, companies 
need to create channels for positive word-of-mouth as well as simplify and incentivize the use of such channels. The importance of reference stakeholders is revealed in the following statements:

\section{"I believe that when you are internationalizing, it is very important that you leverage the current stakeholders wherever you can.... You can involve the stakeholders very well and, for example, use them as ambassadors." [Inter- viewee 3, Corporate Reputation Consultant]}

"Then, you have to ask yourself how you can best use your positive stakeholder relations and the positive reputation that you hold at home? That's the core question. Then, I think, you have to create communities and channels in which the stakeholders can communicate with each other." [Interviewee 1, Corporate Reputation Consultant]

A positive home country reputation can best be illustrated to foreign stakeholders through the communication of specific pieces of evidence (i.e., positive employer attractiveness surveys, awards for innovative and sustainable products, among others). Thereby, those points of evidence are particularly credible when they are conveyed through the stakeholders themselves rather than the corporation.

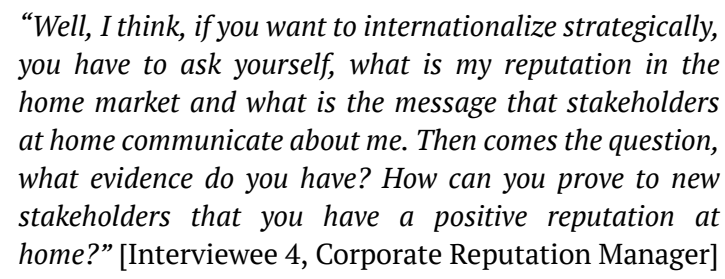

\section{REFERENCE STAKEHOLDERS: MANAGERIAL IMPLICATIONS}

While the notion of utilizing reference consumers in the transfer of reputation between different product markets may be a business practice and has received preliminary attention by scholars (Helm \& Salminen, 2010), it seems promising to broaden this approach and transmit it to firm internationalization and stakeholders in general. Reputation ambassadors should be selected depending on the business goals of the firm in the host market, and companies should not limit themselves to consumers as their reference stakeholders. For instance, companies that have special requirements for human resources in the host country and enjoy a positive reputation among employees in their home market should take advantage of this and use their current employees as reputation ambassadors.

Essentially, there are two driving forces behind the recommendation and implementation of reference stakeholders:

- The reduction of uncertainty: References or ambassadors reduce the risks for prospective, foreign stakeholders by illustrating the benefits of engaging with that firm and by affirming the firm's reliability, trustworthiness and credibility.

- The boundary spanning function: Since reputation is stakeholder-specific and difficult to transfer across national borders, reputation ambassadors may span the boundary between a firm's home country reputation and prospective stakeholders in the host market
(Luo, 2020). Being a reference stakeholder group includes collecting reputational information about the firm, gaining influence among their foreign counterparts, exchanging reputational information, and collaborating with foreign counterparts. In turn, managers can use reference stakeholders' feedback on their foreign counterparts to expand their understanding of the foreign country.

Cross-border reputation transfer cannot be executed by management alone, but should be considered a joint task between the organization and a network of integrated stakeholders that are utilized as references or reputation ambassadors. Consequently, managers are responsible for providing the necessary infrastructure for these reference relationships and for providing stakeholders with guidance and orientation, for instance by providing them with information on the foreign market. Furthermore, managers need to recruit the right home country stakeholders to act as ambassadors, as not all stakeholders may be suitable for the task. This includes a thorough examination of the stakeholder landscape in the foreign country, thereby taking into account the company's business goals associated with the internationalization. Ultimately, managers have to match a stakeholder group from the home market with a foreign stakeholder group that is able to legitimize the company in the host country.

\section{SOCIAL MEDIA: FINDINGS}

The interviewees outlined the relevance of social media as a tool for reputation transfer from home to host countries, as it allows for a dialogical communication with stakeholders and is relatively straightforward to internationalize. They stress the growing impact that social media can have on corporate reputation, for instance because firms can release and disseminate reputation-relevant information. Moreover, social media is described as a potentially powerful monitoring tool that can tap into stakeholder expectations and sentiments and may issue timely warnings when perceptions change. However, social media further holds the risk of unpredictability and uncontrollability. Additionally, while large amounts of reputation-relevant data are generated on social media, firms are frequently lacking the expertise to analyze this data and derive actionable recommendations from it.

"Nowadays, of course, the internet and social media are
important for building reputation and trust. That is not
always easy, because then you are of course obliged to en-
sure that the social media channels are used regularly and
that you post often and engage with your followers. At the
same time, this investment is also an advantage, because
you can easily internationalize the social media channels,
when you go abroad." [Interviewee 5, Corporate Reputa-
tion Manager] "Social media analytics would be so important and useful in terms of transferring reputation between the markets. And, I must say that we should actually use this more strongly. We are not exploiting its full potential yet." [Interviewee 4, Corporate Reputation Manager] 


\section{SOCIAL MEDIA: MANAGERIAL IMPLICATIONS}

Social media is frequently understood as an instrument that helps firms to listen in on what stakeholders communicate about a corporation online (Rust et al., 2021). Here, this study helps to broaden our view on the functions of social media. In fact, it may constitute a tool that can be employed proactively by firms in order to transfer a positive reputation from their home country to a foreign country. However, following the interviews, it can be assumed that the relevance of social media for cross-border reputation transfer is frequently not understood by firms. Therefore, it is recommended to managers to invest in the social media skills of their companies, for example by hiring well-trained social media experts and providing them with the necessary budgets and decision-making skills. Moreover, these specialists should work hand-in-hand with corporate reputation specialists as well as be significantly involved in internationalization projects right from the start.

\section{CONCLUSION}

To conclude this study, its limitations and related boundary conditions need to be discussed. This study was motivated by the argument of firms' need to transfer their positive reputation abroad, thereby neglecting negative firm reputation and its implications for reputation transfer during internationalization. Some statements made by the interviewees suggest that poor reputation in the home country influences an organization's opportunities with regard to internationalization and might impact a firm's approach to reputation transfer. In addition to that, this study builds on interviews with corporate reputation specialists based in Germany, thereby potentially reducing the global generalizability of the findings.

The assumption of a cross-border reputation transfer as the transmission of a core resource from a home country to a host country is a boundary condition. A resource-based perspective of the firm supports this view because it assumes that a firm's competitive advantage can be sustained abroad by transferring established resources from a home to a host market (Barney, 2001; Hughes, Powell, Chung, \& Mellahi, 2017; Mukherjee et al., 2021). However, the underlying assumption of a pre-existing reputation in the home country might not apply to all companies. On the one hand, firms with previous internationalization experience might want to consider another country than the home country as the lead market for reputation transfer. On the other hand, born global firms or early internationalizing corporations might not have had enough time and interaction with stakeholders in a particular market to have developed a positive reputation before going abroad. For these companies, the focus must be on building a positive reputation from the ground up, for instance, through the targeted use of social media.

The underlying assumption of a reputation transfer from one country to another did not take into account the effect of individual characteristics of these countries (e.g. their development status) on a firm's ability to transfer reputa- tion. Following extant research that there could be crosscultural differences in how the reputation of firms is constructed (Gardberg, 2006), in particular the ability to use reference stakeholders might differ for emerging market firms and traditional market firms. While a positive home country reputation is a prerequisite for internationalization for emerging market firms (Mukherjee, Makarius, \& Stevens, 2021), it is likely that stakeholders in traditional markets might not directly be willing to rely on the perceptions and assessments of stakeholders from emerging markets when an emerging market firm internationalizes into their country. A recommendation for these emerging market companies could be that they select reference stakeholders who can substantiate the firm's positive reputation with rather technical points of evidence assuming that such type of proof is independent from the countries' development status.

For the management of internationalizing companies, the implications of this article lie in gaining an understanding of their current reputation among the variety of stakeholders, recognizing which current stakeholders should be empowered to act as references or ambassadors towards prospective, foreign stakeholders, and understanding how social media can be an important tool for reputation transfer. Here, future research can support practitioners by developing implications for the design and the use of corporate reputation monitoring. Moreover, with regard to both the selection and potential training of reference stakeholders, as well as the design and maintenance of communication channels between corporate ambassadors and foreign stakeholders, future research should provide managers with actionable recommendations.

\section{ACKNOWLEDGEMENTS}

I thank my doctoral advisor, Professor Dr. Dirk Holtbrügge, for his constructive comments on this manuscript and a related article, and for his continued mentorship and guidance on my doctoral dissertation. Furthermore, I thank my interview partners for openly and trustingly sharing their knowledge and experience with me. I learnt a lot about corporate reputation and beyond from talking to you.

\section{ABOUT THE AUTHOR}

Theresa Bernhard, M.Sc. is a doctoral student and Research and Teaching Associate at the Department of International Management at the Friedrich-Alexander University Erlangen-Nürnberg in Germany. Her research interests are in the areas of individual and corporate reputation as well as global mobility.

Submitted: January 30, 2021 EST, Accepted: September 12, 2021 EST 
This is an open-access article distributed under the terms of the Creative Commons Attribution 4.0 International License (CCBY-4.0). View this license's legal deed at http://creativecommons.org/licenses/by/4.0 and legal code at http://creativecommons.org/licenses/by/4.0/legalcode for more information. 


\section{REFERENCES}

Barney, J. B. 2001. Resource-based theories of competitive advantage: A ten-year retrospective on the resource-based view. Journal of Management, 27(6): 643-650.

Deephouse, D. L., Newburry, W., \& Soleimani, A. 2016. The effects of institutional development and national culture on cross-national differences in corporate reputation. Journal of World Business, 51(3): 463-473.

Gardberg, N. A. 2006. Reputatie, Reputation, Réputation, Reputazione, Ruf: A Cross-Cultural Qualitative Analysis of Construct and Instrument Equivalence. Corporate Reputation Review, 9(1): 39-61.

Helm, S., \& Salminen, R. T. 2010. Basking in reflected glory: Using customer reference relationships to build reputation in industrial markets. Journal of

Marketing Management, 39(5): 737-743.

Hughes, M., Powell, T. H., Chung, L., \& Mellahi, K. 2017. Institutional and Resource-based Explanations for Subsidiary Performance. British Journal of Management, 28: 407-424.

Johanson, J., \& Vahlne, J.-E. 2009. The Uppsala internationalization process model revisited: From liability of foreignness to liability of outsidership. Journal of International Business Studies, 40(9): 1411-1431.

Luo, Y. 2020. Adaptive learning in international business. Journal of International Business Studies, 51(9): 1547-1567.

Makarius, E. E., \& Stevens, C. E. 2019. Drivers of collective human capital flow: The impact of reputation and labor market conditions. Journal of Management, 45(3): 1145-1172.
Mukherjee, D., Makarius, E. E., \& Stevens, C. E. 2021. A reputation transfer perspective on the internationalization of emerging market firms. Journal of Business Research, 123: 568-579.

Newburry, W., Deephouse, D. L., \& Gardberg, N. A. 2019. Global aspects of reputation and strategic management. In D. L. Deephouse, N. A. Gardberg, \& W. Newburry (Eds.), Global Aspects of Reputation and Strategic Management: 1-20. Bingley, UK: Emerald Publishing.

Norheim-Hansen, A., \& Meschi, P.-X. 2020. Deescalate commitment? Firm responses to the threat of negative reputation spillovers from partners' environmental misconduct. Journal of Business Ethics. https://doi.org/10.1007/s10551-020-04543-z.

Paruchuri, S., Pollock, T. G., \& Kumar, N. 2019. On the tip of the brain: Understanding when negative reputational events can have positive reputation spillovers, and for how long. Strategic Management Journal, 40(12): 1965-1983.

Rindova, V. P., Williamson, I. O., Petkova, A. P., \& Sever, J. M. 2005. Being good or being known: An empirical examination of the dimensions, antecedents, and consequences of organizational reputation. Academy of Management Journal, 48(6): 1033-1049.

Roberts, P. W., \& Dowling, G. R. 2002. Corporate reputation and sustained superior financial performance. Strategic Management Journal, 23(12): 1077-1093.

Rust, R. T., Rand, W., Huang, M.-H., Stephen, A. T., Brooks, G., et al. 2021. Real-Time Brand Reputation Tracking Using Social Media. Journal of Marketing, 85(4): 21-43.

Soleimani, A., Schneper, W. D., \& Newburry, W. 2014. The impact of stakeholder power on corporate reputation: A cross-country corporate governance perspective. Organization Science, 25(4): 991-1008. 